\title{
Effect estimation of stem density and LAI on the evapotranspiration rate from forest stand
}

\author{
K. Tamai \\ Forestry \& Forest Products Research Institute, Japan
}

\begin{abstract}
The estimation model was constructed to estimate the evapotranspiration and canopy interception from the forest stand using the parameters showing the forest structure such as stem density, tree height and leaf area index. This model is expected to have the ability to estimate the effect of forest management such as stem thinning and leaf amount control. Comparing the calculated rate by this model and the observed rate in previous studies, the model can estimate the evapotranspiration and canopy interception. The effect of air temperature rise on the potential water resources was also estimated. Its decrease ratio was calculated to be around $11-13 \%$.
\end{abstract}

Keywords: Penman-Monteith equation, roughness length, zero plane replacement.

\section{Introduction}

It has been one of the major topic in Japan to adapt the forest management such as stem thinning or leaf amount control for purpose of water resource management. It is said for strong dry season does not exist in Japan on the other hand, soil drought is usually not the limitation of transpiration in Japan. When soil drought limitation of the transpiration is not recognized, the amount of potential water resources defined to be annual precipitation minus annual evapotranspiration is used as the index of water resources for any forest stands (e.g. Sawano [1]). In this strategy, the estimation of evapotranspiration rate is very important to estimate the amount of potential water resources. Moreover, it is necessary to estimate the evapotranspiration using the parameters showing the forest structure such as stem density, tree height and leaf area index. If so, we 
can estimate the amount potential water resources for each forest stand, or predict the effect of forest management on the amount of water resources.

Some methods are proposed to estimate the evapotranspiration rate from the forest stands using the forest micro meteorological data (e.g. Monteith [2], Shuttleworth and Calder [3]). However, most of them do not use the parameters showing the forest structure such as stem density, tree height and leaf area index. Thus, it is difficult to estimate the changes of evapotranspiration rate by forest managements, such as stem thinning or leaf amount control in direct.

Among the parameters using in Penman-Monteith equation (Monteith [2]), roughness length and zero plane replacement show the exchange efficiency of vapor between forest canopy and atmosphere, and surface conductance shows the stomata openness. Nakai et al. [4] reported the dependency of roughness length and zero plane replacement on stem density and tree height. Moreover, Stewart [5] proposed the equation to estimate the surface conductance that surface conductance and leaf area index are in the proportional relation. As the feature of evapotranspiration phenomenon from forest stands, canopy interception process to evaporate the intercepted rain water from the canopy surface to the atmosphere is important (Mulder [6]). The calculated values with Penman-Monteith equation means the canopy interception when $\mathrm{g}_{\mathrm{c}}$ is fixed to be infinity. Moreover, Teklehaimanot et al. [7] reported the equation to show the relation between canopy interception rate and stem density.

In this paper, the estimation model for evapotranspiration rate is constructed using the parameters of stem density, tree height and leaf are index, by connecting the previous studies. The constructed model can predict the change of evapotranspiration and potential water resources by forest management such as stem thinning and leaf amount control.

\section{Model}

Evapotranspiration is consisted with transpiration and canopy interception loss. When canopy is dry, trees transpirate through stomata. When canopy is wet with rain, water evaporates from the canopy surface to the atmosphere.

\subsection{Transpiration}

Transpiration rate was calculated using the Penman-Monteith equation as eqn (1) proposed by Monteith [2]:

$$
\mathrm{IE}=\frac{\Delta \mathrm{R}_{\mathrm{e}}+\rho \mathrm{C}_{\mathrm{p}} \delta \mathrm{q} \mathrm{g}_{\mathrm{a}}}{\Delta+\gamma\left(1+\frac{g_{a}}{g_{c}}\right)}
$$

where $1 E$ is the transpiration rate, $R_{e}$ is the effective radiation, $g_{c}$ is the surface conductance, $g_{a}$ is the aerodynamic conductance, $\rho$ is the air density, $\delta q$ is the vapor pressure deficit, $\mathrm{C}_{\mathrm{p}}$ is the specific heat of air at constant pressure, and $\Delta$ is the slope of the saturation vapor pressure at air temperature, $\gamma$ is the psychrometric constant. 
The value of $g_{a}$ was obtained from eqn (2):

$$
g_{a}=\frac{\kappa^{2} u(z)}{\left(\ln \frac{z-d}{z_{0}}\right)^{2}}
$$

where $u(z)$ is the wind speed, $z$ is the wind speed observation height, $d$ is the zero plane replacement, $\mathrm{z}_{0}$ is roughness length, and $\kappa$ is the von Karman constant.

Eqns (3) and (4) is the approximation formula showing the dependency of $z_{0}$ and $\mathrm{d}$, respectively, on stem density $\left(\mathrm{d}_{\mathrm{s}} ; \mathrm{stem} \mathrm{ha}^{-1}\right)$ and tree height $(\mathrm{h} ; \mathrm{m})$, derived from the figures in Nakai et al. [4].

$$
\begin{gathered}
\frac{z_{0}}{h}=0.2007 \exp \left(-0.0003 d_{s}-0.0001\right) \\
\frac{d}{h}=0.2327 \ln \left(d_{s}\right)-1.1859
\end{gathered}
$$

Stewart [5] proposed the eqn (5) as following for surface conductance:

$$
\mathrm{g}_{\mathrm{c}}=\alpha \operatorname{LAI} \mathrm{f}(\mathrm{S}) \mathrm{f}(\delta \mathrm{q}) \mathrm{f}(\mathrm{T}) \mathrm{f}(\delta \theta)
$$

where $\mathrm{LAI}$ is the leaf area index, $\mathrm{S}$ is the solar radiation, $\mathrm{T}$ is the air temperature, $\delta \theta$ is the soil moisture deficit, and f represents the functions of each of the environmental variables; $\alpha$ is a constant.

$f(S), f(\delta q)$ and $f(T)$ are used as eqns (6)-(8), respectively, proposed by Komatsu [8].

$$
\begin{gathered}
\mathrm{f}(\mathrm{S})=\frac{1180 S}{1000+180 S} \\
\mathrm{f}(\delta \mathrm{q})=\frac{E X P(-0.569 \delta q)}{E X P(-0.569)} \\
\mathrm{f}(\mathrm{T})=\frac{39(T-5)}{25(T+9)}
\end{gathered}
$$

The unit of $\mathrm{S}, \delta \mathrm{q}$ and $\mathrm{T}$ in these equations are $\mathrm{W} \mathrm{m} \mathrm{m}^{-2}, \mathrm{kPa}$ and ${ }^{\circ} \mathrm{C}$, respectively. As strong dry season does not exist in Japan, soil drought is usually not the limitation of transpiration in Japan. Thus, $f(\delta \theta)$ is fixed to be 1 in this paper. $\alpha$ is also fixed to be 12.36 in this paper.

\subsection{Canopy interception}

The calculated rate by eqn (1) with $g_{c}$ to be infinity can be regarded as canopy interception $\left(\mathrm{lE}_{\mathrm{i}}\right)$. On the other hand, Teklehaimanot et al. [7] reported the relations between dens and $\mathrm{lE}_{\mathrm{i}}$ as eqn (9).

$$
\mathrm{IE}_{\mathrm{i}}=\frac{8.6 \times 0.026 d_{s}}{8.6+0.026 d_{s}}
$$

Combined with both, potential rate of $1 \mathrm{E}_{\mathrm{i}}$ was calculated with eqn (10) in this study. 


$$
\mathrm{IE}_{\mathrm{i}}=\frac{\Delta\left(\mathrm{R}_{\mathrm{n}}-\mathrm{G}\right)+\rho \mathrm{C}_{\mathrm{p}} \delta \mathrm{q} \mathrm{g}_{\mathrm{a}}}{\Delta+\gamma} \frac{8.6 \times 0.026 d_{s}}{8.6+0.026 d_{s}}
$$

However, larger water than precipitation $(\mathrm{P})$ cannot be intercepted by canopy, $1 E_{i}$ rate was judged to be equal to $P$, when calculated potential rate of $1 E_{i}$ was larger than $\mathrm{P}$ in a calculation unit time.

\subsection{Calculation method}

The necessary data to calculation are precipitation, effective radiation, solar radiation, air temperature, vapor pressure deficit and wind speed as weather condition, and stem density, tree height and leaf area index as forest stand situation.

The model was constructed for stem density and leaf area index to be input individually, to estimate the effect by forest management such as stem thinning and leaf amount control. However, this paper focuses on the model construction and their calculation ability, not on the effect estimation of forest management. Thus the relation between stem density and leaf area index was settled as Figure 1 in this study. $\mathrm{H}$ is also fixed to be $12.6 \mathrm{~m}$ in this paper. Thus evapotranspiration was defined to be the amount of vapor passing up through the $14.6 \mathrm{~m}$ height plane from forest canopy to atmosphere.

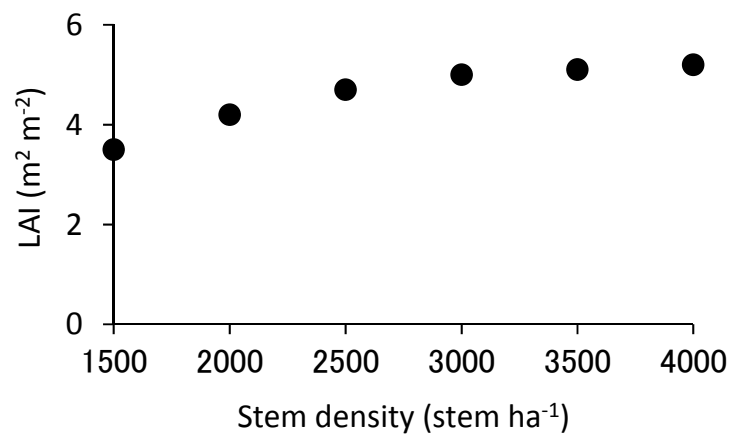

Figure 1: The values of stem density and Leaf Area Index (LAI) used in the model calculation.

\section{Site description and observation method}

The weather condition hourly data was observed in the Main weather station of Takaragawa Forest Watershed Experimental Station located in central Japan $\left(36^{\circ}\right.$ $51^{\prime} \mathrm{N}, 139^{\circ} 01^{\prime} \mathrm{E}, \mathrm{ASL} 861 \mathrm{~m}$ ) in May-October 2011 to be no snow period. The amount of precipitation was $1,267.0 \mathrm{~mm}$ in this period. Figure 2 shows their monthly averaged or integrated values. The observation height of sensors are $6.5 \mathrm{~m}$ for wind speed, $5.59 \mathrm{~m}$ for net radiation and solar radiation, and $4.82 \mathrm{~m}$ for air temperature and relative humidity. 

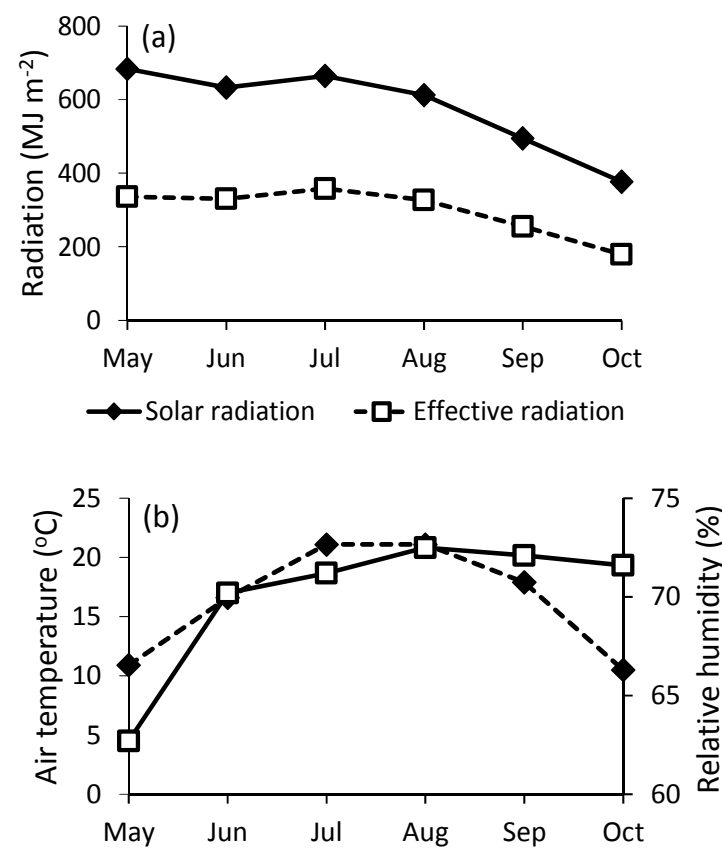

$-\diamond-$ Air temperature $\quad-\square-$ Relative humidity

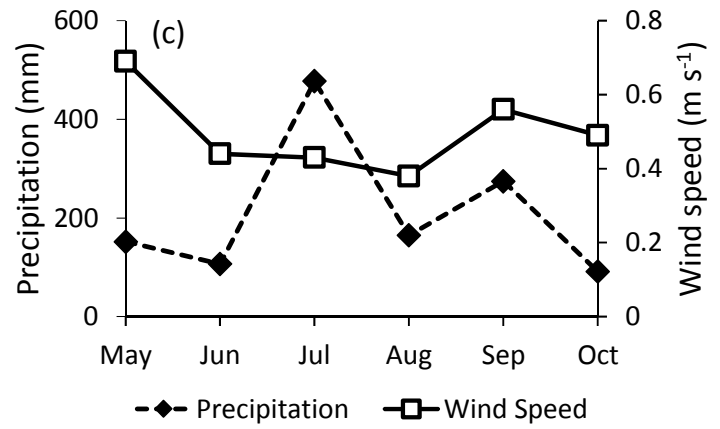

Figure 2: Average or integrate monthly weather data used in the model calculation observed in Takaragawa Forest Watershed Experimental Station in May-October, 2011. (a) Integrated monthly solar radiation and effective radiation, (b) Average monthly air temperature and relative humidity, (c) Integrate precipitation and average wind speed.

Additionally, the change of $\mathrm{lE}$ and potential water resources were estimated in this paper with the vertical air temperature by the global warming effect. The vertical air temperature was $4^{\circ} \mathrm{C}$ higher than $\mathrm{T}$ observed in Takaragawa in each hour. The value of relative humidity was not changed. However raised air 
temperature cause to increase the value of VPD in calculation. The raised temperature to be $4^{\circ} \mathrm{C}$ derived from the $\mathrm{A} 1 \mathrm{~F} 1$ scenario of global warming.

\section{Results and discussions}

\subsection{The rates of evapotranspiration and canopy interception}

The evapotranspiration and rainfall interception between May and October are calculated to be $480-580 \mathrm{~mm}$ and $210-220 \mathrm{~mm}$, respectively, in the range of stem density to be $1500-4000$ number $\mathrm{ha}^{-1}$ (Figures 3 and 4). As the amount of $P$ was $1267.0 \mathrm{~mm}$ in this period, percentages of the $1 \mathrm{E}$ and $\mathrm{lE}_{\mathrm{i}}$ over $\mathrm{P}$ were around 38$46 \%$ and $17 \%$, respectively. These values and percentages are compared with the previous studies derived from the observation of $1 \mathrm{E}$ and $\mathrm{IEi}$ between May and October in Japanese forest.

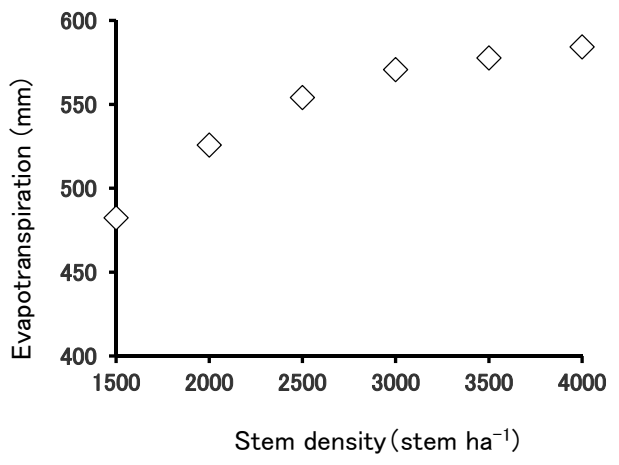

Figure 3: Calculated evapotranspiration in each stem density.

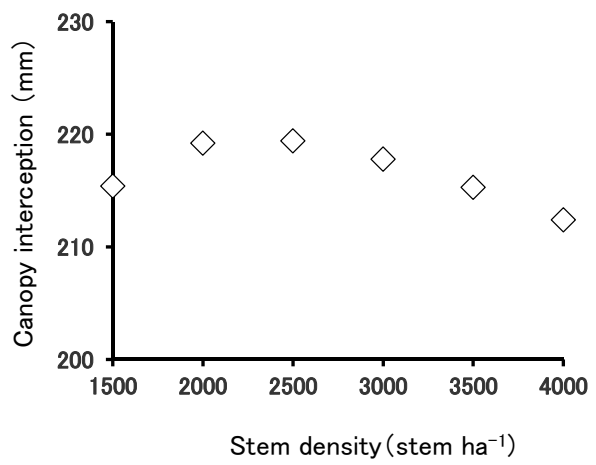

Figure 4: Calculated canopy interception in each stem density. 
Kiryu Catchment ( $34^{\circ} 58^{\prime} \mathrm{N}, 136^{\circ} 0^{\prime} \mathrm{E}$, ASL 190-255m, Area 5.99 ha) is covered with evergreen coniferous forest consisted with Japanese red pine (Pinus densiflora SIEB, et ZUCC) and Japanese cypress (Chamaecyparis obtuse SIEB et ZUCC). Suzuki [9] reported the rates of $1 \mathrm{E}$ derived from the method of the short time period water budget using observed precipitation and discharge water volume from the catchment, and $\mathrm{lE}_{\mathrm{i}}$ derived from the tank model. Tank model is consisted with tanks corresponding to canopy and stem of trees. From the balance of each tanks based on the observed $\mathrm{P}, 1 \mathrm{E}_{\mathrm{i}}$ was estimated. Summing the average monthly rates between May and October, 1972-1976 reported by Suzuki [9], $1 \mathrm{E}, 1 \mathrm{E}_{\mathrm{i}}$ and $\mathrm{P}$ were $514.0 \mathrm{~mm}, 199.2 \mathrm{~mm}$ and $1,185.0 \mathrm{~mm}$, respectively. Percentages of the $\mathrm{lE}$ and $1 \mathrm{E}_{\mathrm{i}}$ over $\mathrm{P}$ were around $43 \%$ and $17 \%$, respectively.

Yamashiro Catchment ( $34^{\circ} 47^{\prime} \mathrm{N}, 135^{\circ} 51^{\prime} \mathrm{E}$, ASL 190-260m, Area $1.6 \mathrm{ha}$ ) is covered with secondary deciduous broad leaved forest. Most dominant species is oak (Quercus serrata Thunb. Ex Murray). Abe et al. [10] reported the monthly rates of $\mathrm{lE}$ derived from the method of the short time period water budget, and $1 E_{i}$ derived from the difference between observed $\mathrm{P}$ and observed precipitation on the forest floor. Summing the monthly rates between May and October, 1989 reported by $\mathrm{Abe}$ et al. [10], $1 \mathrm{E}, 1 \mathrm{E}_{\mathrm{i}}$ and $\mathrm{P}$ were $564.0 \mathrm{~mm}, 139.6 \mathrm{~mm}$ and $1,181.0 \mathrm{~mm}$, respectively. Percentages of the $1 \mathrm{E}$ and $1 \mathrm{E}_{\mathrm{i}}$ over $\mathrm{P}$ were around $48 \%$ and $12 \%$, respectively.

The calculated rates by the model constructed in this paper are almost equal to those reported by Suzuki [9] and Abe et al. [10]. Thus it can be judged that the model have the ability to estimate the $1 \mathrm{E}$ and $\mathrm{lE}_{\mathrm{i}}$ properly.

\subsection{Changes of evapotranspiration and canopy interception by forest management}

Next, the differences of $1 E$ and $1 E_{i}$ among the different $d_{s}$ are compared with the previous reports by Kubota et al. [11] and Nobuhiro et al. [12]. Hitach Ohta Experimental Watershed $\left(36^{\circ} 34^{\prime} \mathrm{N}, 140^{\circ} 35^{\prime} \mathrm{E}\right.$, ASL 310-340m Area $0.88 \mathrm{ha}$ ) is covered with Japanese ceder (Cryptomeria japonica). The stem thinning was performed in 2009 from 2,229 stem ha ${ }^{-1}$ to 1,113 stem ha-1. Kubota et al. [11] and Nobuhiro et al. [12] reported the changes of $1 \mathrm{E}$ and $\mathrm{lE}_{\mathrm{i}}$, respectively, before and after stem thinning.

Kubota et al. [11] estimated $\mathrm{lE}$ before and after stem thinning derived from the water budget and paired catchment experiment and reported that $\mathrm{lE}$ after thinning was reduced to around $80 \%$ of before thinning. The calculated $\mathrm{lE}$ by the

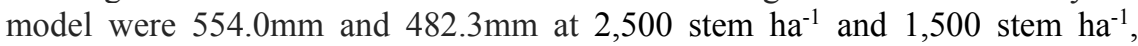
respectively. The latter is around $87 \%$ of the former. The decreased percentage calculated in the model is less than that in Kubota et al. [11] derived from the observation.

On the other hand, Nobuhiro et al. [12] reported that the percentage of through fall over the precipitation increased from $70-75 \%$ before thinning to 80 $90 \%$ after thinning. Rain water reaches to a forest floor by 2 ways, through fall (pass through between the canopy) and stem flow (run down on the stem). In general, the volume of through fall is much more than stem flow. For example, Abe et al. [10] reported the percentages of through fall and stem flow over the 
precipitation to be $80 \%$ and $7 \%$, respectively, in Yamashiro catchment. Under the assumption that stem flow can be ignored, the report by Nobuhiro et al. [12] can be interpreted that the percentage of $\mathrm{lE}_{\mathrm{i}}$ over $\mathrm{P}$ decreased from $25-30 \%$ before thinning to $10-20 \%$ after thinning. The calculated $\mathrm{lE}_{\mathrm{i}}$ by the model were $219.4 \mathrm{~mm}$ and $215.4 \mathrm{~mm}$ at $2,500 \mathrm{stem} \mathrm{ha}^{-1}$ and 1,500 stem ha $^{-1}$, respectively. The percentages of $1 \mathrm{E}_{\mathrm{i}}$ over $\mathrm{P}$ were around $17 \%$ in both $\mathrm{d}_{\mathrm{s}}$, much less than that reported by Nobuhiro et al. [12] derived from the observation. Thus, it is judged that the model constructed in this paper has to be improved to estimate the change of canopy interception.

\subsection{Effect of global warming on evapotranspiration and potential water resources}

Figure 5 shows the increase rate of $1 \mathrm{E}$ calculated by the model due to that $\mathrm{T}$ in Takaragawa rises $4^{\circ} \mathrm{C}$ in observed weather data in Takaragawa. In the range of $\mathrm{d}_{\mathrm{s}}$ to be $1,500-2,000$ stem $^{-1} a^{-1}$, the increased rate of $1 \mathrm{E}$ was around $72-83 \mathrm{~mm}$ in May-October, 2011 caused that $\mathrm{T}$ rises $4^{\circ} \mathrm{C}$.

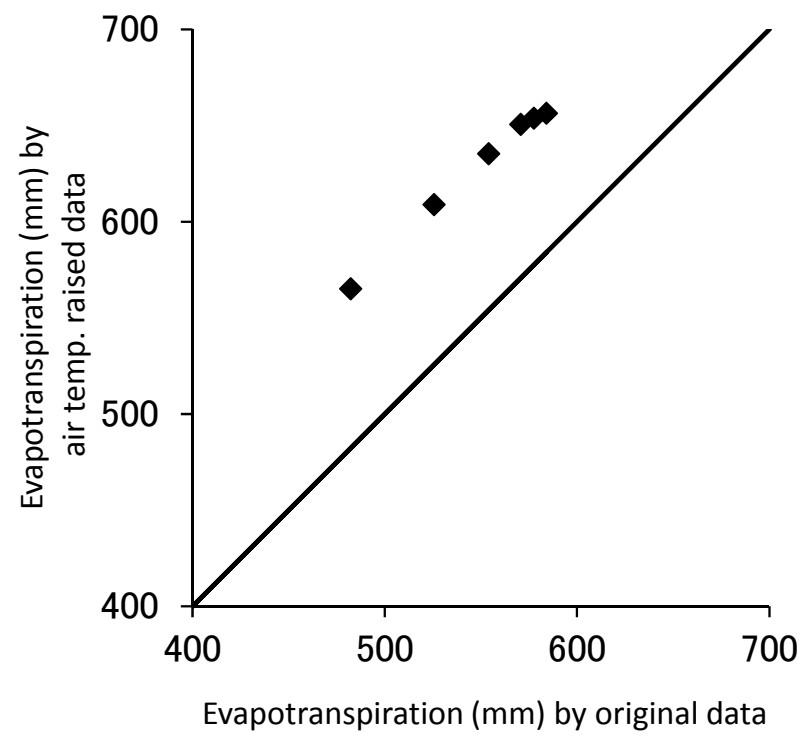

Figure 5: Comparison of evapotranspiration rate calculated with the original weather data and $4^{\circ} \mathrm{C}$ raised air temperature data. Solid line shows that both rates are equal.

The potential water resources is defined to be the difference between $\mathrm{P}$ and $\mathrm{IE}$. Thus the increase of $\mathrm{IE}$ leads the decrease of potential water resources. In the present situation using the original observed weather data in Takaragawa, potential water resources are estimated to be around $615-715 \mathrm{~mm}$. In case using the warming weather data that $\mathrm{T}$ rises $4^{\circ} \mathrm{C}$, potential water resources decreased to 
be around 540-630mm (Figure 6). The decreased ratio was calculated to be around $11-13 \%$.

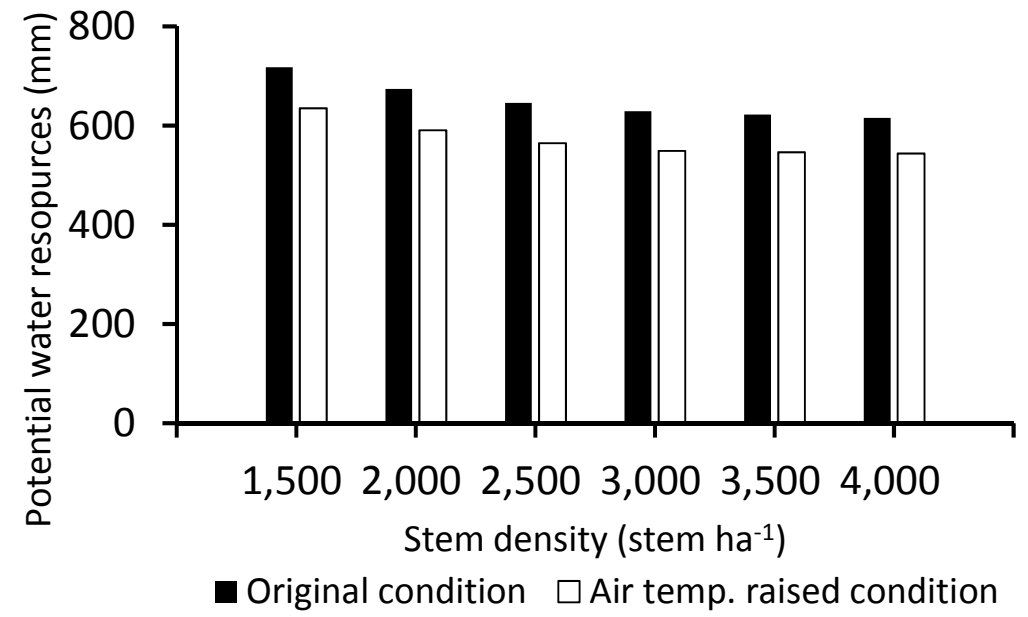

Figure 6: Comparison of potential water resources in case of original condition and raised air temperature condition.

\section{References}

[1] Sawano, S. Distribution of potential water resources in forested area, Mekong river basin, Water Science, 58(2), pp. 17-32 (in Japanese).

[2] Monteith, J. L. Evapotranspiration and environment. The state and movement of water in living organs, ed. Fogg, G. E., Soc. Exp. Biol. Symp., 19, pp. 205-224, 1965.

[3] Shuttleworth, H. P. \& Calder, I. R. Has the Priestry-Taylor equation any relevance to forest evaporation? J. Appl. Meteorol. 18, pp. 639-644, 1979.

[4] Nakai, T., Sumida, A., Daikoku, K., Matsumoto, K., van der Molen, M. K., Kodama, Y., Kononov, A. V., Maximov, T. C., Dolman, A. J., Yabuki, H., Hara, T. \& Ohta, T. Parameterisation of aerodynamic roughness over boreal, cool- and warm-temperate forests. Agricultural and forest meteorology, 148, pp. 1916-1925, 2008.

[5] Stewart, J. B. Modelling surface conductance of pine forest, Agr. Forest Meteorol., 43, pp. 19-35, 1988.

[6] Mulder, J. P. M. Simulating interception loss using standard meteorological data. The Forest-Atmosphere Interaction, ed. Hutchison, B. A. and Hicks, B. B., D. Reidel Publishing Company: Dordecht, pp. 177196, 1985.

[7] Teklehaimanot, Z., Jarvis, P. G. \& Ledger, D. C. Rainfall interception and boundary layer conductance in relation to tree spacing. Journal of Hydrology, 123, pp. 261-278, 1991. 
[8] Komatsu, H. A general method of parameterizing the big-leaf model to predict the dry-canopy evaporation rate of individual coniferous forest stands. Hydrological Processes, 89, pp. 346-359, 2004.

[9] Suzuki, M. Evapotranspiration from a small catchment in hilly mountains (I) seasonal variations in evapotranspiration, rainfall interception and transpiration. Journal of the Japanese Forestry Society, 62, pp. 46-53, 1980.

[10] Abe, T., Hattori, S., Tamai, K. \& Goto, Y. Characteristics of water balance in secondary broad-leaved forest. Applied forest science, 6, pp. 175-178, 1997 (in Japanese).

[11] Kubota, T., Tsuboyama, Y., Nobuhiro, T. \& Sawano, S. Change of evapotranspiration due to stand thinning in the Hitachi Ohta Experimental Watershed. Journal of Japanese Forestry Society, 95, pp. 37-41 (in Japanese).

[12] Nobuhiro, T., Tsuboyama, Y., Kubota, T. \& Tamai, K. Change in canopy structure and throughfall accompanying thinning in a Japanese cypress forest, in northern Ibaraki. Kanto Shnrin Kenkyu, 64, pp. 41-44, 2013 (in Japanese). 